\section{Effect of Aging on Meiosis Progression, Developmental Competence and DNA Double-Strand Breaks in Mouse Oocytes}

\author{
Lei Gao', Gong-xue Jia ${ }^{2}$, Zheng-yuan Huang ${ }^{1}$, Ming-xing Yue ${ }^{3}$, Chao Zhang ${ }^{1}$, \\ Shi-en $\mathrm{Zhu}^{1}$ and Xiang-wei Fu ${ }^{1, *}$ \\ ${ }^{1}$ National Engineering Laboratory for Animal Breeding, Key Laboratory of Animal \\ Genetics, Breeding and Reproduction of the Ministry of Agriculture, Beijing Key \\ Laboratory for Animal Genetic Improvement, College of Animal Science and \\ Technology, China Agricultural University, Beijing 100193, P.R. China \\ ${ }^{2}$ Qinghai Key Laboratory of Animal Ecological Genomics, Key Laboratory of \\ Adaptation and Evolution of Plateau Biota, Northwest Institute of Plateau Biology, \\ Chinese Academy of Sciences, Xining 810008, China \\ ${ }^{3}$ College of Bioengineering, Beijing Polytechnic, Beijing, 100176, P.R. China
}

Lei Gao and Gong-xue Jia have contributed equally to this work.

\begin{abstract}
A B S T R A C T
This study investigated the effect of aging on meiosis progression, embryo developmental competence and DNA double-strand breaks (DSBs) in mouse oocytes and resultant early embryos. Germinal vesicle (GV) oocytes were first cultured to monitor the progression of germinal vesicle breakdown (GVBD) and polar body extrusion (PBE) during in vitro maturation (IVM), then the harvested metaphase II (MII) oocytes were parthenogenetically activated to evaluate pronuclear $(\mathrm{PN})$ formation of parthenogenetic embryo and embryo development. The cytoplasmic maturation was examined by measuring the intracellular reactive oxygen species (ROS) and glutathione (GSH). DNA DSBs were examined by immunostaining of pi-H2AX, the marker of DNA DSBs. The results showed that the GVBD rates were similar in oocytes of young and aged mice. Polar body extrusion was significantly delayed in aged mice $(\mathrm{P}<0.05)$, however the rate of polar body extrusion was similar to that of young mice at $16 \mathrm{~h}$ of IVM. Moreover, PN formation of parthenogenetic embryo was significantly delayed in aged mice $(\mathrm{P}<0.05)$. Afterward the two groups obtained similar results with respect to the percentages of activated oocytes, 2-cell embryos and blastocysts. The cytoplasmic maturation of MII oocytes and blastocysts in aged mice were significantly compromised to those of young mice $(\mathrm{P}<0.05)$. Furthermore, GV oocytes, 2-cell embryos and blastocysts showed significantly higher relative intensities of pi-H2AX in aged mice (P $<0.05$ ). Taken together, our result indicate that aging disturbed oocyte maturation and parthenogenetic embryo development, which could be related to insufficient cytoplasmic maturation and worsening DNA DSBs in oocytes and early embryos.
\end{abstract}
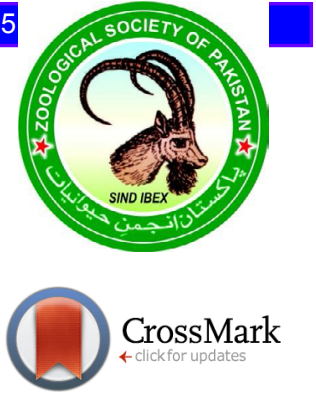

Article Information

Received 16 August 2018

Revised 02 December 2018

Accepted 24 December 2018

Available online 06 April 2020

Authors' Contribution

XF, GJ and LG designed and organized this research. GJ and LG performed the in vitro maturation, oocyte parthenogenetic activation (PA) and embryo in vitro culture. LG, GJ and $\mathrm{ZH}$ performed the measurement of intracellular reactive oxygen species (ROS) and glutathione (GSH) levels. LG, ZH and MY performed immunofluorescent microscopy experiment. LG, CZ and GJ analysed the obtained data. XF and SZ interpreted the results. XF, LG and GJ wrote the manuscript.

Key words

Aging, DNA double-strand breaks,

Embryo, Mouse, Oocyte maturation.

\section{INTRODUCTION}

A lthough both men and women suffering aging effect, fecundability has a stronger correlation with maternal age (Rothman et al., 2013). In aged women, $20-30 \%$ of ovulated oocytes are aneuploid (Nagaoka et al., 2012). Despite the rapid progress in assisted reproductive technology increasing the possibility to overcome the reproductive problems, the sterility of advanced maternal age is still an important question (Tarin et al., 2014).

\footnotetext{
Corresponding author: xiangweifu@126.com 0030-9923/2020/0004-1463 \$ 9.00/0

Copyright 2020 Zoological Society of Pakistan
}

There is significant reduction in the possibility of fertilization and pregnancy with advanced maternal age in human beings and mice (Schwartz and Mayaux, 1982; Cui et al., 2013). Even if pregnancy takes place, older females have greater risks of miscarriage and nondisjunction (Te and Pearson, 2002; Herbert et al., 2015). These phenomena are ascribed to a complex series of factors including inappropriate hormone (folliclestimulating hormone) secretion (McTavish et al., 2007), deteriorative uterine apparatus (Schreuder et al., 2006) and shrinking oocyte pool (Fu et al., 2014). However, oocyte competency is thought to be the primary determinant of female reproductive aging (Krey and Grifo, 2001; Keefe et $a l ., 2015)$, considering that oocytes donations from young 
to older women nearly completely abrogate the effects of aging on fertility (Cohen et al., 1999).

Compared to young female mice, there are substantially increased aneuploidy rates (Sebestova et al., 2012; Fu et al., 2014) and serious DNA damage in aged mice oocytes (Fujino et al., 1996). When chromosomes are broken, the DNA damage checkpoint is activated to allow extra time for repairing damaged DNA (Sancar et al., 2004; Carroll and Marangos, 2013; Rinaldi et al., 2017). Recent reports confirm that oocytes carrying DNA damage associated with DNA double-strand breaks (DSBs) arrest in meiosis I through activation of the spindle assembly checkpoint, which results in anaphase-promoting complex (APC) inhibition (Collins et al., 2015; Marangos et al., 2015; Lane et al., 2017). Furthermore, DSBs also disrupt oocyte spindle assembly (Wang et al., 2016) and microtubule-kinetochore attachment during metaphase of the meiosis I (MI) (Mayer et al., 2016), which is harmful to the segregation of homologous chromosomes and may result in aneuploidy (Lu et al., 2017).

Besides, studies have also revealed that accumulation of reactive oxygen species (ROS) could induce DNA damage which may give rise to dramatic decline in oocyte cytoplasmic quality (Menezo et al., 2010; Collins and Jones, 2016; Meldrum et al., 2016). Reactive oxygen species (ROS) increases with age (Kregel and Zhang, 2007), owing in part to lowered endogenous antioxidant defenses generating glutathione (GSH) levels (Suh et al., 2004; Noreen, 2018). GSH, an important indicator of oocyte cytoplasmic maturation (Curnow et al., 2010), plays an important role in protecting the cell against oxidative damage by eliminating the ROS (de Matos et $a l ., 2000)$. Impaired GSH synthesis has been reported to compromise developmental potential of mouse oocytes (Jiao et al., 2013).

ROS and DNA damage effect accumulate with age (Garinis et al., 2008; Li et al., 2008; Meldrum et al., 2016). Oocytes are the special cells which arrested at G2/ prophase in the ovary for the entire reproductive lifespan. Thus oocyte is particularly vulnerable to DNA damage. The histone $\mathrm{H} 2 \mathrm{~A}$ variant $\mathrm{H} 2 \mathrm{AX}$ is phosphorylated on serine residue 139 at DNA damage sites, which is widely accepted as a marker for DNADSBs (Rogakou et al., 1998). Hence, in this study we examined the dynamic changes of pi-H2AX during oocyte maturation and early embryo development, to investigate whether DNA DSBs were involved in the compromised oocyte meiosis progression and embryos developmental potential in aged mice.

\section{MATERIALS AND METHODS}

Unless otherwise stated, all chemicals and media were purchased from Sigma-Aldrich (MO, USA). All procedures contributing to this work were approved by the Animal Ethics Committee of the China Agricultural University and comply with the ethical principles of animal experimentation adopted by this committee.

\section{Oocyte collection and in vitro maturation (IVM)}

Swiss CD1 mice (Vital River Laboratory Animal Technology Co. Ltd., China) were housed in a room at $20^{\circ} \mathrm{C}$ to $22^{\circ} \mathrm{C}$ for $12 \mathrm{~h}$ (8AM-8PM) light and 12 $\mathrm{h}$ dark cycle. Mice were superovulated with $10 \mathrm{IU}$ (intraperitoneal) equine chorionic gonadotropin (eCG; Ningbo Hormone Products Co., China). According to previous report, germinal vesicle $(\mathrm{GV})$ oocytes were isolated from "young" (6-week-old) or "aged" (9-monthold) female Swiss CD1 mice at $48 \mathrm{~h}$ after eCG treatment and transferred into M2 medium supplemented with $3 \mathrm{mg} /$ $\mathrm{ml}$ bovine serum albumin (Flurkey, 2007). Then oocytes were rinsed thoroughly and placed in M16 medium containing $10 \%$ fetal bovine serum (FBS), $10 \mu \mathrm{g} / \mathrm{mL}$ $\mathrm{FSH}, 10 \mu \mathrm{g} / \mathrm{mL} \mathrm{LH}, 0.01 \mu \mathrm{g} / \mathrm{mL}$ epidermal growth factor (EGF) and $0.23 \mathrm{mM}$ sodium pyruvate for IVM, covered with mineral oil and maintained in an incubator (at $37^{\circ} \mathrm{C}$ in an atmosphere of $5 \% \mathrm{CO}_{2}$ and at maximum humidity). Germinal vesicle breakdown (GVBD) was observed every $0.5 \mathrm{~h}$ beginning at $0 \mathrm{~h}$ of IVM and polar body extrusion (PBE) was assessed every $1 \mathrm{~h}$ since $8 \mathrm{~h}$ of IVM, until the incidence rates did not increase further.

Oocyte parthenogenetic activation (PA) and embryo development

At $16 \mathrm{~h}$ of IVM, metaphase II (MII) oocytes with polar bodies were chosen and activated incalcium-free human tubal fluid (HTF) medium containing $10 \mathrm{mM} \mathrm{SrCl}_{2}$ and $5 \mathrm{mg} / \mathrm{ml}$ cytochalasin D (CD) for $2.5 \mathrm{~h}$. Then oocytes were transferred into regular HTF medium supplemented with $5 \mathrm{mg} / \mathrm{ml} \mathrm{CD}$ for $3.5 \mathrm{~h}$. Finally, activated oocytes were cultured in drops of KSOM medium (Millipore, MA, USA). The pronuclear (PN) formation of parthenogenetic embryo was evaluated every $1 \mathrm{~h}$ from $3 \mathrm{~h}$ post activation until rising to a peak. Thereafter, the percentages of activated oocytes, 2-cell embryos and blastocysts were assessed at $8 \mathrm{~h}, 24 \mathrm{~h}$ and $96 \mathrm{~h}$ post activation, respectively.

Measurement of intracellular reactive oxygen species (ROS) and glutathione (GSH) levels

To measure ROS level, cells were incubated in dark with M2 supplemented with $1 \mathrm{mM}$ 2',7'-dichlorodihydrofluorescein diacetate ( $\mathrm{H}_{2}$ DCFDA) for $20 \mathrm{~min}$ at $37^{\circ} \mathrm{C}$, washed three times with phosphatebuffered saline (PBS) and placed into $50 \mu \mathrm{l}$ droplets. The fluorescence was measured under an epifluorescence 
microscope with a filter at $460 \mathrm{~nm}$ excitation. ImageJ software (National Institutes of Health, MA, USA) was used to analyse fluorescence images. The GSH level was measured by $10 \mu \mathrm{M}$ 4-chloromethyl-6.8-difluoro-7hydroxycoumarin (Cell-Tracker Blue) with a filter at 370 nm excitation, the experimental procedure was the same as the ROS measurement described above.

\section{Immunofluorescent microscopy}

Immunostaining analysis was carried out as described previously (Lin et al., 2014) with some modification. After brief washing, oocytes or embryos were fixed with $3.7 \%(\mathrm{w} / \mathrm{v})$ paraformaldehyde in PBS for $30 \mathrm{~min}$ and permeabilized with $0.5 \%(\mathrm{v} / \mathrm{v})$ Triton X-100 in PBS for $20 \mathrm{~min}$. Subsequently, oocytes or embryos were blocked with $1 \%(\mathrm{w} / \mathrm{v}) \mathrm{BSA}$ in PBS for $1 \mathrm{~h}$ before incubation with anti-phosphorylated H2AX at Ser139 (diluted 1:200; Bioworld, Beijing, China) overnight at $4^{\circ} \mathrm{C}$. Following several washes, oocytes or embryos were incubated with fluorescein isothiocyanate (FITC) conjugated anti-rabbit secondary antibody (diluted 1:200; Beyotime, Shanghai, China) for $1 \mathrm{~h}$ at room temperature. Finally, extensively rinsed oocytes or embryos were mounted on a glass slide in a drop of Vectashield anti-bleaching solutioncontaining $3 \mu \mathrm{g} / \mathrm{ml} \mathrm{4}$, 6-diamidino-2-phenylindole (DAPI) (Vector Laboratories, CA, USA) and examined on a laser scanning

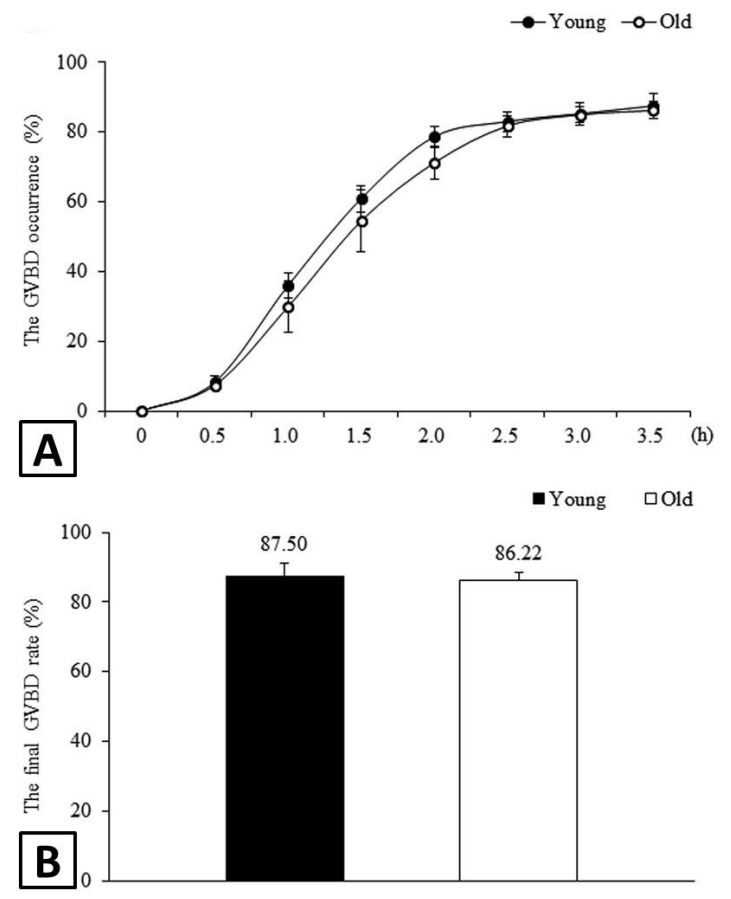

confocal microscope (Nikon, Tokyo, Japan). The relative intensity of pi-H2AX was calculated using the ratio of antibody signal to DNA signal after subtraction of cytoplasm background fluorescence.

\section{Statistical analysis}

All experiments were repeated at least three times. Statistical analysis was conducted by one-way analysis of variance followed by Duncan's test using SPSS software (IBM, NY, USA). Data were expressed as the mean \pm standard error and a value of $P<0.05$ was considered significant.

\section{RESULTS}

Aging did not prevent GVBD but delayed PBE (poler body extrusion)

To investigate whether aging affected oocyte meiosis resumption and final maturation, the progression of GVBD and PBE were traced successively during IVM. As shown in Figure 1A and B, most oocytes had undergone GVBD before $3.5 \mathrm{~h}$ of IVM in the aged and young groups (86.22 $\pm 2.38 \%$ vs. $87.50 \pm 3.71 \%$ ). However, the PBE started after $10 \mathrm{~h}$ of IVM in the aged group, which was delayed about an hour than that of the young group. Furthermore, the PBE rate in the aged group remained significantly below that of the young group at 10,11 and $12 \mathrm{~h}$ during

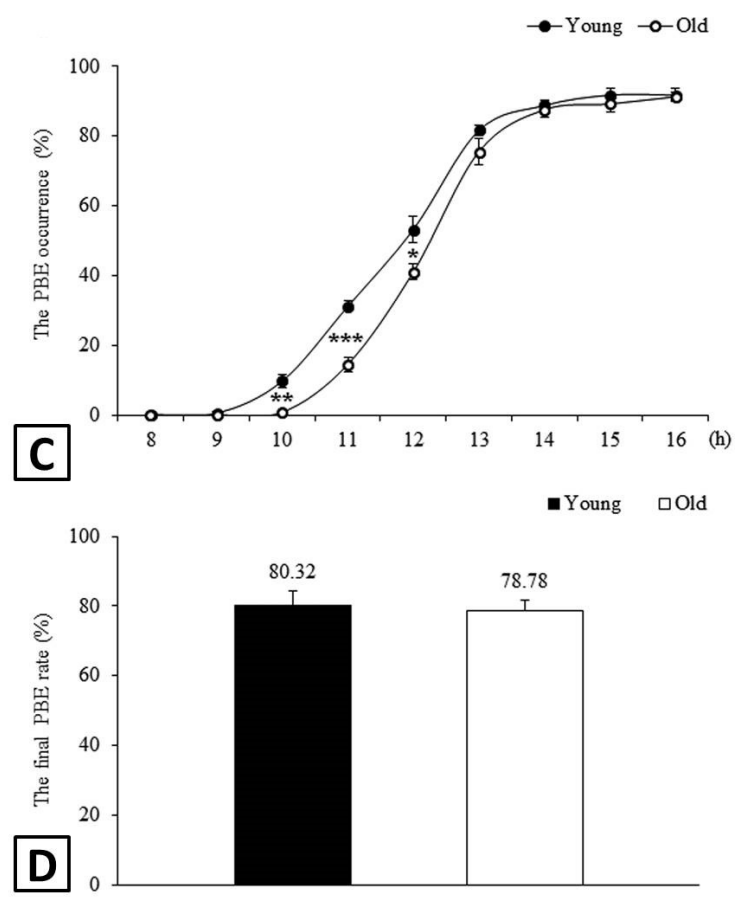

Fig. 1. Kinetics of GVBD and PBE during oocyte maturation. Shown are the temporal trends of GVBD (A) and PBE (C) occurrence during IVM and the final rates of GVBD (B) and PBE (D) in oocytes. Number of oocytes analysed in total: $\mathrm{n}=150$ in the young 
group; $\mathrm{n}=147$ in the aged group. ${ }^{*} P<0.05, * * P<0.01, * * * P<0.001$. IVM $(0.69 \pm 0.69 \%, 12.52 \pm 1.99 \%$ and $35.39 \pm 2.41 \%$ vs. $8.59 \pm 1.73 \%, 27.07 \pm 1.32 \%$ and $46.39 \pm 3.50 \%, \quad P<0.05$; Fig. 1C), although they finally achieved a similar incidence at $16 \mathrm{~h}$ of IVM $(78.78 \pm 2.75 \%$ vs. $80.32 \pm 3.90 \%$; Fig. 1D).

\section{Aging delayed PN formation but did not affect embryo} development

To further determine whether mature oocytes went through normal embryo development in aged mice, the

developmental process of PA embryos was monitored. Similar to PBE, PN formation of parthenogenetic embryo also showed a significant decline at 3, 4, 5 and $6 \mathrm{~h}$ post activation in the aged group $(13.79 \pm 1.26 \%, 29.24 \pm 2.19 \%$, $57.45 \pm 2.50 \%$ and $78.72 \pm 1.26 \%$ vs. $36.30 \pm 1.48 \%, 59.77 \pm$ $4.63 \%, 75.79 \pm 2.74 \%$ and $85.71 \pm 2.71 \%, P<0.05$, Fig. $2 \mathrm{~A}$ ). Afterward the two groups obtained similar results with respect to the percentages of activated oocytes, 2-cell embryos and blastocysts (Fig. 2B).
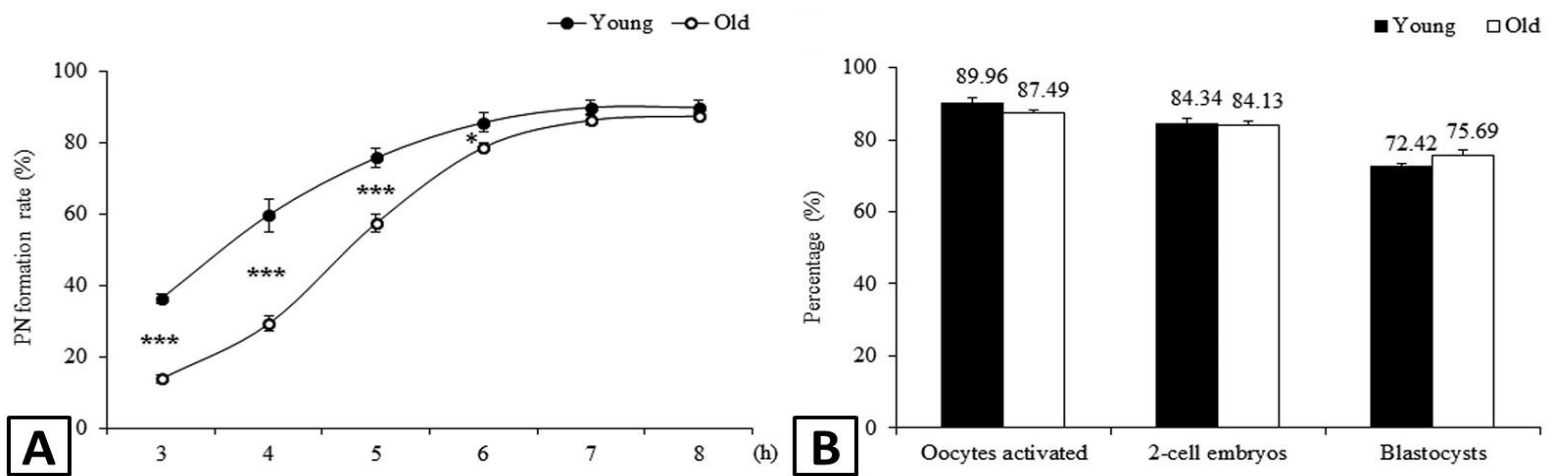

Fig. 2. Kinetics of PN formation in PA embryos. Shown were the temporal trends of PN formation (A) and the percentages of activated oocytes, 2-cell embryos and blastocysts (B). Number of oocytes analysed in total: $n=193$ in the young group; $n=183$ in the aged group.
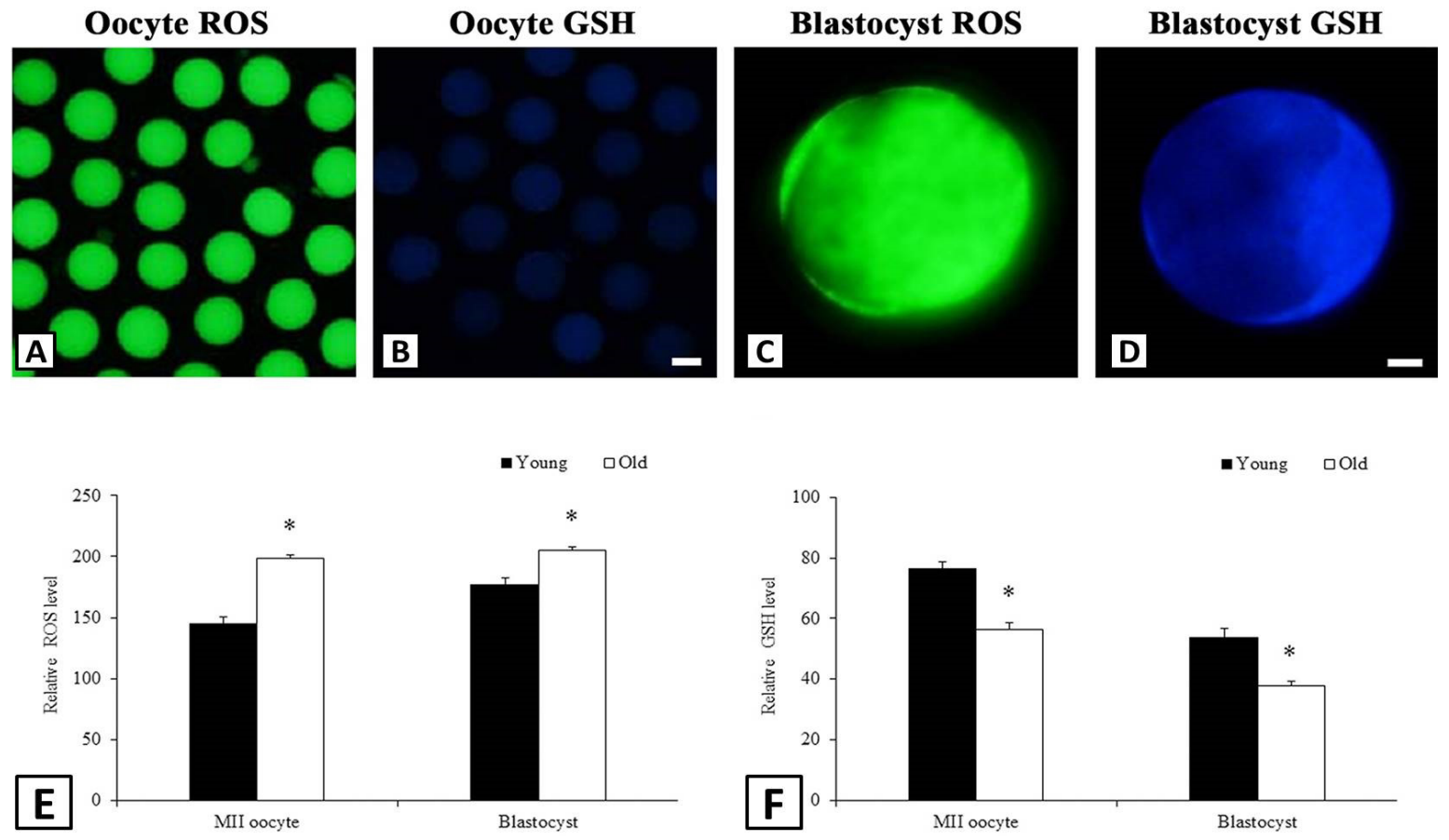

Fig. 3. Intracellular ROS and GSH levels in MII oocytes and blastocysts. Shown were representative images of ROS (A) and GSH (B) in MII oocytes. C and D were the representative images of ROS and GSH, respectively in blastocysts. The quantitative results from fluorescence intensities of ROS (E) and GSH (F) in MII oocytes and blastocysts, respectively. At least 25 MII oocytes or 
blastocysts were analysed for each treatment per group. Scale bar is $50 \mu \mathrm{m}$ in A and B and $20 \mu \mathrm{m}$ in C and D.

Aging compromised cytoplasmic maturation in oocytes and early embryos

Although the percentage of GV oocytes developed to MII stage or blastocyst stage showed no significant difference between two groups, intracellular ROS and GSH levels were detected in MII oocytes and blastocysts. The aged group showed remarkably increased ROS levels and declined GSH levels both in MII oocytes and blastocysts $(P<0.05$, Fig. 3$)$, meaning that their cytoplasmic maturation was substantially insufficient as compared with that of the young group.
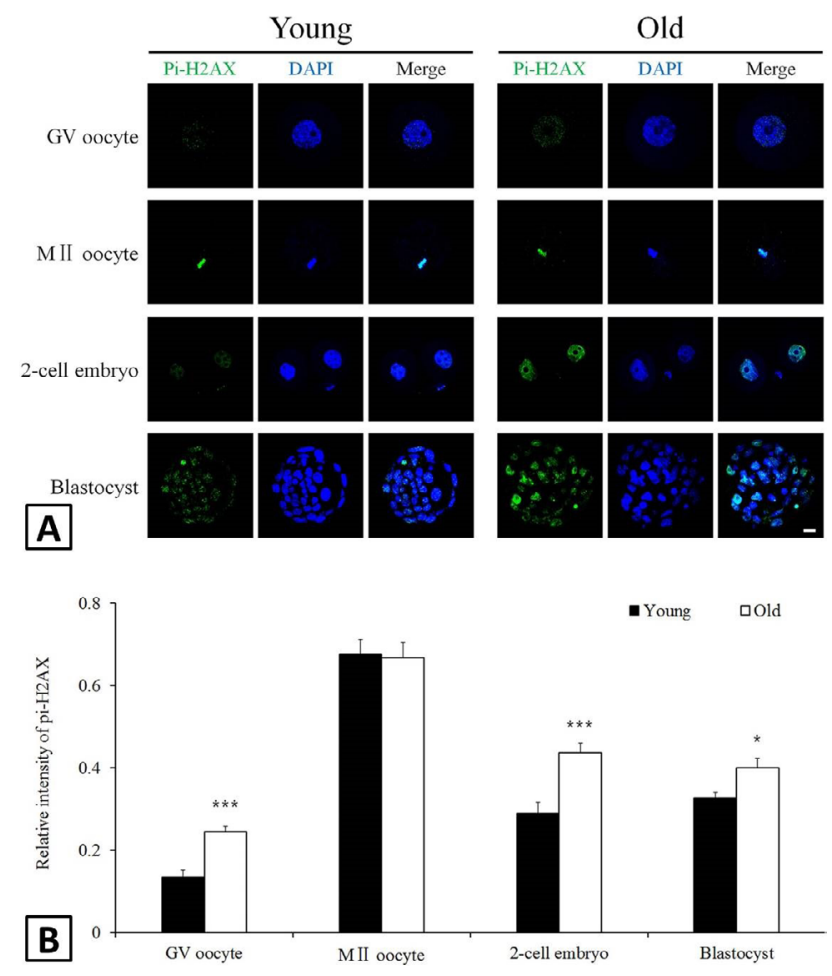

Fig. 4. Immunofluorescent staining of DNA DSBs in oocytes and early embryos. A, representative images of oocytes and early embryos stained with pi-H2AX antibody (green) and DAPI (blue). Scale bar $=20 \mu \mathrm{m}$. B, relative intensities of pi-H2AX signals normalized against DNA signals. At least 25 oocytes or early embryos were analysed at each stage per group.

Aging caused the worsening of DNA DSBs in oocytes and early embryos

Given that cell cycle was postponed during oocyte maturation and parthenogenetic embryo development in aged mice, it is doubtful whether the delay was related to DNA DSBs. To address this possibility, the signal of piH2AX was detectedin oocytes and early embryos (Fig. 4A). The aged group showed stronger relative intensities of pi-
$\mathrm{H} 2 \mathrm{AX}$ in GV oocytes, 2-cell embryos and blastocysts than the young group $(P<0.05)$, while their relative intensities of pi-H2AX were similar in MII oocytes (Fig. 4B).

\section{DISCUSSION}

Our results indicated that the progression of PBE was delayed and the level of DSBs was significantly increased in aged mice oocytes (Figs. 1C, 4A). Previously, oocytes with high level of DSBs exhibit a delay in the time of emission of the first polar body (Ma et al., 2013; Lin et al., 2014). It had been observed that DNA damage induced before GVBD would lead to a MI arrest through activation of the spindle assembly checkpoint, which results in anaphase-promoting complex (APC) inhibition (Collins et al., 2015; Marangos et al., 2015; Lane et al., 2017). The oocytes with high level of DSBs also disrupts microtubule-kinetochore attachment (Mayer et al., 2016), which would raise the rate of oocyte aneuploidy (Lu et al., 2017). According, our previous research has observed the increased aneuploidy rates in aged mice oocytes (Fu et al., 2014).

DSBs existed in aged GV oocytes do not prevent meiotic maturation. In this study, there was no significant difference on the rates of PBE at $16 \mathrm{~h}$ of IVM (Fig. 1D). Some studies provide evidence that the SAC activity is compromised in old oocytes which maybe a likely explanation for the inability of aged oocytes to establish an efficient MI checkpoint in response to DNA damage (Riris et al., 2014; Marangos et al., 2015). Recent study shows that escaping DNA damage checkpoint in maternal aging may be one of the causes of increased chromosome anomalies in oocytes from older mothers (Marangos et al., 2015; Sakakibara et al., 2015).

Recent studies have revealed that the accumulation of ROS cause DNA damage in the aged oocytes during long periods of dictyate arrest and if it is not repaired, the DNA damage may give rise to dramatic declines in oocyte cytoplasmic quality (Menezo et al., 2010; Collins and Jones, 2016; Meldrum et al., 2016). Accordingly, our results showed oocytes cytoplasmic maturation was substantially compromised as remarkably increased ROS levels and declined GSH levels in aged mice MII oocytes (Fig. 3). ROS increases with age (Kregel and Zhang, 2007), owing in part to lowered endogenous antioxidant defenses generating glutathione (GSH) levels (Suh et al., 2004) which compromise the developmental potential of mouse oocytes (Jiao et al., 2013).

The compromise in oocyte cytoplasmic maturation could be harmful to embryo development (Krey and Grifo, 2001; Keefe et al., 2015). We observed that PN 
formation of parthenogenetic embryo was delayed in aged mice (Fig. 2A). Similar result was also observed by other researchers in zygotes of middle-aged and aged mice (Cui et al., 2013). The cell cycle arrest found in zygotic development could be triggered by induced DNA DSBs (Carroll and Marangos, 2013). The arrest is mandatory to allow DNA repair activity in order to avoid mutation in all kinds of germ line (Goldmann et al., 2018). In this study, aged mice still had higher levels of DNA DSBs in 2-cell embryos and blastocysts in compared to the young mice (Fig. 4B), indicated the unrepaired DNA damage in oocytes could persist into embryo development stage (Derijck et al., 2008).

In addition, the DNA DSBs in early embryos do not influence the subsequently embryo development. We confirmed the degrees of DNADSBs in 2-cell embryos were higher in aged than young mice, however, the two groups obtained similar results with respect to the percentages of blastocysts (Fig. 2B). This probably because the embryo development through cells mitosis with the same property as somatic cells, which do not halt mitosis in response to DNA damage, and instead respond in G1 by either repairing their DNA or undergoing apoptosis (Hustedt and Durocher, 2017).

\section{CONCLUSION}

In conclusion, our study demonstrated that oocyte maturation and embryo development could be compromised with advanced maternal age, and it could be related to insufficient cytoplasmic maturation and worsening DNA DSBs in oocytes and early embryos.

\section{ACKNOWLEDGEMENTS}

This work was supported by the National Transgenic Creature Breeding Grand Project (2016ZX08008-003) and National Natural Science Foundation Project of China (No. 31101714 and 31372307). JIA Gong-xue was funded by CPSF-CAS Joint foundation for Postdoctoral Fellows and CAS "Light of West China" Program. The authors would like to thank Edanz Editing for proofreading this manuscript.

\section{Statement of conflict of interest}

The authors declare no conflict of interest.

\section{REFERENCES}

Carroll, J. and Marangos, P., 2013. The DNA damage response in mammalian oocytes. Front. Genet., 4: 117. https://doi.org/10.3389/fgene.2013.00117
Cohen, M.A., Lindheim, S.R. and Sauer, M.V., 1999. Donor age is paramount to success in oocyte donation. Hum. Reprod., 14: 2755-2758. https:// doi.org/10.1093/humrep/14.11.2755

Collins, J.K., Lane, S.I., Merriman, J.A. and Jones, K.T., 2015. DNA damage induces a meiotic arrest in mouse oocytes mediated by the spindle assembly checkpoint. Nat. Commun., 6: 8553. https://doi. org/10.1038/ncomms9553

Collins, J.K. and Jones, K.T., 2016. DNA damage responses in mammalian oocytes. Reproduction, 152: 15-22. https://doi.org/10.1530/REP-16-0069

Crawford, N.M. and Steiner, A.Z., 2015. Age-related infertility. Obstet. Gynecol. Clin. N. Am., 42: 15-25. https://doi.org/10.1016/j.ogc.2014.09.005

Cui, L.B., Zhou, X.Y., Zhao, Z.J., Li, Q., Huang, X.Y. and Sun, F.Z., 2013. The Kunming mouse: As a model for age-related decline in female fertility in human. Zygote, 21: 367-376. https://doi. org/10.1017/S0967199412000123

Curnow, E.C., Ryan, J.P., Saunders, D.M. and Hayes, E.S., 2010. Oocyte glutathione and fertilisation outcome of Macaca nemestrina and Macaca fascicularis in in vivo- and in vitro-matured oocytes. Reprod. Fertil. Dev., 22: 1032-1040. https://doi. org/10.1071/RD09308

de Matos, D.G. and Furnus, C.C., 2000. The importance of having high glutathione (GSH) level after bovine in vitro maturation on embryo development: Effect of b-mercaptoethanol, cysteine and cystine. Theriogenology, 53: 761-771. https://doi. org/10.1016/S0093-691X(99)00278-2

Derijck, A., van der Heijden, G., Giele, M., Philippens, M. and de Boer, P., 2008. DNA double-strand break repair in parental chromatin of mouse zygotes, the first cell cycle as an origin of de novo mutation. Hum. Mol. Genet., 17: 1922-1937. https://doi. org $/ 10.1093 / \mathrm{hmg} / \mathrm{ddn} 090$

Flurkey, K., Currer, J.M. and Harrison, D.E., 2007. Mouse models in aging research, Chapter 20. In: The mouse in biomedical research (eds. J. Fox, S. Barthold, M. Davisson, C. Newcomer, F. Quimby and A. Smith), Vol. III, $2^{\text {nd }}$ edition. Academic Press, USA, pp. 637-672. https://doi.org/10.1016/B978012369454-6/50074-1

Fu, X., Cheng, J., Hou, Y. and Zhu, S., 2014. The association between the oocyte pool and aneuploidy: a comparative study of the reproductive potential of young and aged mice. J. Assist. Reprod. Genet., 31: 323-331. https://doi.org/10.1007/s10815-0130160-5

Fujino, Y., Ozaki, K., Yamamasu, S., Ito, F., Matsuoka, 
I., Hayashi, E., Nakamura, H., Ogita, S., Sato, E. and Inoue, M., 1996. DNA fragmentation of oocytes in aged mice. Hum. Reprod., 11: 1480-1483. https:// doi.org/10.1093/oxfordjournals.humrep.a019421

Garinis, G.A., van der Horst, G.T., Vijg, J. and Hoeijmakers, J.H., 2008. DNA damage and ageing: New-age ideas for an age-old problem. Nat. Cell Biol., 10: 1241-1247. https://doi.org/10.1038/ ncb1108-1241

Goldmann, J.M., Seplyarskiy, V.B., Wong, W.S.W., Vilboux, T., Neerincx, P.B., Bodian, D.L., Solomon, B.D., Veltman, J.A., Deeken, J.F., Gilissen, C. and Niederhuber, J.E., 2018. Germline de novo mutation clusters arise during oocyte aging in genomic regions with high double-strand-break incidence. Nat. Genet., 4: 487-492. https://doi. org/10.1038/s41588-018-0071-6

Herbert, M., Kalleas, D., Cooney, D., Lamb, M. and Lister, L., 2015. Meiosis and maternal aging: insights from aneuploid oocytes and trisomy births. Cold Spring Harb. Perspect. Biol., 7: a17970. https://doi.org/10.1101/cshperspect.a017970

Lin, F., Ma, X.S., Wang, Z.B., Wang, Z.W., Luo, Y.B., Huang, L., Jiang, Z.Z., Hu, M.W., Schatten, H. and Sun, Q.Y., 2014. Different fates of oocytes with DNA double-strand breaks in vitro and in vivo. Cell Cycle, 13: 2674-2680. https://doi.org/10.4161/153 84101.2015.945375

Hustedt, N. and Durocher, D., 2017. The control of DNA repair by the cell cycle. Nat. Cell Biol., 19: 1-9. https://doi.org/10.1038/ncb3452

Jiao, G.Z., Cao, X.Y., Cui, W., Lian, H.Y., Miao, Y.L., Wu, X.F., Han, D. and Tan, J.H., 2013. Developmental potential of prepubertal mouse oocytes is compromised due mainly to their impaired synthesis of glutathione. PLoS One, 8: e58018. https://doi.org/10.1371/journal. pone. 0058018

Kalmbach, K.H., Fontes, A.D., Dracxler, R.C., Knier, T.W., Seth-Smith, M.L., Wang, F., Liu, L. and Keefe, D.L., 2013. Telomeres and human reproduction. Fertil. Steril., 99: 23-29. https://doi. org/10.1016/j.fertnstert.2012.11.039

Keefe, D., Kumar, M. and Kalmbach, K., 2015. Oocyte competency is the key to embryo potential. Fertil. Steril., 103: 317-322. https://doi.org/10.1016/j. fertnstert.2014.12.115

Kregel, K.C. and Zhang, H.J., 2007. An integrated view of oxidative stress in aging: Basic mechanisms, functional effects, and pathological considerations. Am. J. Physiol. Regul. Integr. Comp. Physiol., 292: 18-36. https://doi.org/10.1152/ajpregu.00327.2006
Krey, L.C. and Grifo, J.A., 2001. Poor embryo quality: The answer lies (mostly) in the egg. Fertil. Steril., 75: 466-468. https://doi.org/10.1016/S00150282(00)01778-7

Lane, S.I.R., Morgan, S.L., Wu, T., Collins, J.K., Merriman, J.A., ElInati, E., Turner, J.M. and Jones, K.T., 2017. DNA damage induces a kinetochore-based ATM/ATR-independent SAC arrest unique to the first meiotic division in mouse oocytes. Development, 19: 3475-3486. https://doi. org/10.1242/dev.153965

Li, H., Mitchell, J.R. and Hasty, P., 2008. DNA doublestrand breaks: A potential causative factor for mammalian aging? Mech. Ageing Dev., 129: 416424. https://doi.org/10.1016/j.mad.2008.02.002

Lin, F., Ma, X.S., Wang, Z.B., Wang, Z.W., Luo, Y.B., Huang, L., Jiang, Z.Z., Hu, M.W., Lu, Y., Dai, X., Zhang, M., Miao, Y., Zhou, C., Cui, Z. and Xiong, B., 2017. Cohesin acetyl transferase Esco 2 regulates SAC and kinetochore functions via maintaining H4K16 acetylation during mouse oocyte meiosis. Nucl. Acids Res., 16: 9388-9397.

Lu, Y., Dai, X., Zhang, M., Miao, Y., Zhou, C., Cui, Z. and Xiong, B., 2017. Cohesin acetyltransferase esco2 regulates sac and kinetochore functions via maintaining $\mathrm{h} 4 \mathrm{k} 16$ acetylation during mouse oocyte meiosis. Nucleic Acids Res., 45: 9388-9397. https://www.ncbi.nlm.nih.gov/pubmed/28934466

Ma, J.Y., Ou, Y.C., Wang, Z.W., Wang, Z.B., Jiang, Z.Z., Luo, S.M., Hou, Y., Liu, Z.H., Schatten, H. and Sun, Q.Y., 2013. The effects of DNA doublestrand breaks on mouse oocyte meiotic maturation. Cell Cycle, 12: 1233-1241. https://doi.org/10.4161/ cc. 24311

Marangos, P., Stevense, M., Niaka, K., Lagoudaki, M., Nabti, I., Jessberger, R. and Carroll, J., 2015. DNA damage-induced metaphase I arrest is mediated by the spindle assembly checkpoint and maternal age. Nat. Commun., 6: 8706. https://doi.org/10.1038/ ncomms9706

Mayer, A., Baran, V., Sakakibara, Y., Brzakova, A., Ferencova, I., Motlik, J., Kitajima, T.S., Schultz R.M. and Solc, P., 2016. DNA damage response during mouse oocyte maturation. Cell Cycle, 15: 546-558. https://www.ncbi.nlm.nih.gov/ pubmed/26745237

McTavish, K.J., Jimenez, M., Walters, K.A., Spaliviero, J., Groome, N.P., Themmen, A.P., Visser, J.A., Handelsman, D.J. and Allan, C.M., 2007. Rising follicle-stimulating hormone levels with age accelerate female reproductive failure. Endocrinology, 148: 4432-4439. https://doi. 
org/10.1210/en.2007-0046

Meldrum, D.R., Casper, R.F., Diez-Juan, A., Simon, C., Domar, A.D. and Frydman, R., 2016. Aging and the environment affect gamete and embryo potential: Can we intervene? Fertil. Steril., 105: 548-559. https://doi.org/10.1016/j.fertnstert.2016.01.013

Menezo, Y., Dale, B. and Cohen, M., 2010. DNA damage and repair in human oocytes and embryos: A review. Zygote, 18: 357-365. https://doi. org/10.1017/S0967199410000286

Miao, Y., Kikuchi, K., Sun, Q. and Schatten, H., 2009. Oocyte aging: Cellular and molecular changes, developmental potential and reversal possibility. Hum. Reprod. Update, 15: 573-585. https://doi. org/10.1093/humupd/dmp014

Nagaoka, S.I., Hassold, T.J. and Hunt, P.A., 2012. Human aneuploidy: Mechanisms and new insights into an age-old problem. Nat. Rev. Genet., 13: 493504. https://doi.org/10.1038/nrg3245

Noreen, A., Bukhari, D.A. and Rehman, A. 2018. Reactive oxygen species: Synthesis and their relationship with cancer. Pakistan J. Zool., 50: 1951-1963.

Rinaldi, V.D., Bolcun-Filas, E., Kogo, H., Kurahashi, H. and Schimenti, J.C., 2017. The DNA damage checkpoint eliminates mouse oocytes with chromosome synapsis failure. Mol. Cell, 6: 10261036. https://doi.org/10.1016/j.molcel.2017.07.027

Riris, S., Webster, P. and Homer, H., 2014. Digital multiplexed mRNA analysis of functionally important genes in single human oocytes and correlation of changes in transcript levels with oocyte protein expression. Fertil. Steril., 101: 857-864. https://doi.org/10.1016/j.fertnstert.2013.11.125

Rogakou, E.P., Pilch, D.R., Orr, A.H., Ivanova, V.S. and Bonner, W.M., 1998. DNA double-stranded breaks induce histone $\mathrm{H} 2 \mathrm{AX}$ phosphorylation on serine 139. J. biol. Chem., 273: 5858-5868. https://doi. org/10.1074/jbc. 273.10 .5858

Rothman, K.J., Wise, L.A., Sorensen, H.T., Riis, A.H., Mikkelsen, E.M. and Hatch, E.E., 2013. Volitional determinants and age-related decline in fecundability: A general population prospective cohort study in Denmark. Fertil. Steril., 99: 1958-1964. https://doi.org/10.1016/j. fertnstert.2013.02.040

Sakakibara, Y., Shu, H., Nakaoka, Y., Kouznetsova, A., Höög, C. and Kitajima, T.S., 2015. Bivalent separation into univalents precedes age-related meiosis I errors in oocytes. Nat. Commun., 6: 7550. https://doi.org/10.1038/ncomms8550

Sancar, A., Lindsey-Boltz, L.A., Unsal-Kacmaz,
K. and Linn, S., 2004. Molecular mechanisms of mammalian DNA repair and the DNA damage checkpoints. Annu. Rev. Biochem., 73: 39-85. https://doi.org/10.1146/annurev. biochem.73.011303.073723

Schreuder, M.F., van Wijk, J.A. and van Delemarre, D.W.H., 2006. Intrauterine growth restriction increases blood pressure and central pulse pressure measured with telemetry in aging rats. J. Hypertens., 24: 1337-1343. https://doi.org/10.1097/01. hjh.0000234114.33025.fd

Schatten, H. and Sun, Q.Y., 2014. Effects of DNA damage and short-term spindle disruption on oocyte meiotic maturation. Histochem. Cell Biol., 142: 185-194. https://doi.org/10.1007/s00418-014$1182-5$

Schwartz, D. and Mayaux, M.J., 1982. Female fecundity as a function of age: Results of artificial insemination in 2193 nulliparous women with azoospermic husbands. Federation CECOS. N. Engl. J. Med., 306: 404-406. https://doi. org/10.1056/NEJM198202183060706

Sebestova, J., Danylevska, A., Novakova, L., Kubelka, M. and Anger, M., 2012. Lack of response to unaligned chromosomes in mammalian female gametes. Cell Cycle, 11: 3011-3018. https://doi. org/10.4161/cc.21398

Suh, J.H., Shenvi, S.V., Dixon, B.M., Liu, H., Jaiswal, A.K., Liu, R.M. and Hagen, T.M., 2004. Decline in transcriptional activity of $\mathrm{Nrf} 2$ causes agerelated loss of glutathione synthesis, which is reversible with lipoic acid. Proc. natl. Acad. Sci. U.S.A., 10: 3381-3386. https://doi.org/10.1073/ pnas.0400282101

Tarin, J.J., Garcia-Perez, M.A. and Cano, A., 2014. Assisted reproductive technology results: Why are live-birth percentages so low? Mol. Reprod. Dev., 81: 568-583. https://doi.org/10.1002/mrd.22340

Te, V.E. and Pearson, P.L., 2002. The variability of female reproductive ageing. Hum. Reprod. Update, 8: 141154. https://doi.org/10.1093/humupd/8.2.141

Wang, H., Luo, Y., Zhao, M.H., Lin, Z., Kwon, J., Cui, X.S. and Kim, N.H., 2016. DNA double-strand breaks disrupted the spindle assembly in porcine oocytes. Mol. Reprod. Dev., 83: 132-143. https:// doi.org/10.1002/mrd.22602

Zhang, T., Zhang, G.L., Ma, J.Y., Qi, S.T., Wang, Z.B., Wang, Z.W., Luo, Y.B., Jiang, Z.Z., Schatten, H. and Sun, Q.Y., 2014. Effects of DNA damage and short-term spindle disruption on oocyte meiotic maturation. Histochem. Cell Biol., 142: 185-194. https://doi.org/10.1007/s00418-014-1182-5 